\title{
Morphological abnormalities in Drosophila with overexpression of human APP gene
}

\author{
Dmitry Rodin*, Olga Bolshakova, Galina Kislik, Svetlana Sarantseva
}

Molecular and Radiation Biophysics Department, National Research Centre "Kurchatov Institute”-B.P. Konstantinov Petersburg

Nuclear Physics Institute, Gatchina, Russia; "Corresponding Author: nomadkml@me.com

Received 16 August 2013; revised 22 September 2013; accepted 5 October 2013

Copyright (C) 2013 Dmitry Rodin et al. This is an open access article distributed under the Creative Commons Attribution License, which permits unrestricted use, distribution, and reproduction in any medium, provided the original work is properly cited.

\begin{abstract}
Alzheimer's disease (AD) is the leading and one of the most severe forms of dementia. Molecular mechanisms underlying AD pathogenesis despite much work on this subject still remain unclear. Cleavage of amyloid precursor protein (APP) to amyloid beta peptide (A-beta) and following formation of amyloid plaques are the key events of Alzheimer's pathology. Thus changes in APP expression and metabolism can lead to pathology development. Here we show that overexpression of human APP in Drosophila neural cells manifests in different morphological abnormalities of Drosophila imago that can be observed immediately after fly eclosion. This observation can help to further understand APP molecular functions and its participation in different molecular pathways.
\end{abstract}

Keywords: Alzheimer's Disease; Drosophila; Amyloid Precursor Protein; Morphological Abnormalities

\section{INTRODUCTION}

A-beta is a major component of one of the pathomorphological hallmarks of AD-senile plaques. According to the amyloid cascade hypothesis, increased A-beta production is the key event that triggers a cascade of reactions leading to neurodegeneration and $\mathrm{AD}$ [1]. However, neurodegeneration level and patient's condition don't always correlate with the amount of amyloid deposits in the patient's brain, which possibly means that there are alternative mechanisms leading to neurodegeneration and disease development [2,3]. Amyloid precursor protein (APP) is an integral membrane protein that can be involved in one of such mechanisms. Overexpression of APP or its malfunction can possibly manifest in neuron- pathology development independently of A-beta [4]. A-beta is a product of APP cleavage and that is why in many studies APP is considered only as a source of Abeta. At the same time its functions remain unclear. There are evidences proclaiming APP participation in processes of neurodegeneration [4], cell adhesion [5], cell signaling [6], chromatin condensation [7] etc.

Earlier we showed that APP overexpression in Drosophila brain leads to different pathological changes that manifest in vacuolization of neuronal tissues [8], degeneration of cholinergic and dopaminergic neurons and disruption of cognitive functions [9].

This study is dedicated to different morphological abnormalities of Drosophila imago caused by overexpression of human APP in nerve cells.

\section{MATERIALS AND METHODS}

\subsection{Drosophila Lines}

The following lines were used: UAS-APP carrying human APP695 (obtained from Drosophila Bloomington Stock Center), UAS-APP-Swedish carrying human APP695 with mutation that leads to familial form of disease (obtained from Drosophila Bloomington Stock Center), UAS-BACE carrying human beta-secretase (kindly provided by R. Reifegerste) APP and APPSwedish were expressed in Drosophila neurons using tissue specific transcription driver elav-GAL4c155.

Flies were kept on standard yeast medium and on medium containing molasses with a higher calorie content at a temperature of $25^{\circ} \mathrm{C}$ and a photoperiod of $12 \mathrm{~h}$.

\subsection{Preparation of Specimens for Light Microscopy}

Light microscopy analysis was performed in order to study morphological changes of wings, abdomen and heads in flies with human APP overexpression.

Morphological changes in fly heads were analyzed on 
previously prepared specimens: $1 \mathrm{~d}$ old flies with removed wings were cleared in $10 \% \mathrm{KOH}$ at $95^{\circ} \mathrm{C}$ for 30 minutes, then fly heads were separated and incubated in 9:1 mix of glycerol and $1 \mathrm{M}$ Tris $\mathrm{HCl} \mathrm{pH} 7.5$ overnight

\subsection{Statistics}

KyPlot software (KyensLab Inc) was used for statisticcal analysis of obtained data. One-way ANOVA was followed by planned multiple comparisons between relevant groups with Tukey-Kramer test.

\section{RESULTS}

APP processing that leads to A-beta production involves cleavage of the protein with $\beta$ - and $\gamma$-secretases. Drosophila has no active $\beta$-secretase (BACE) or its activity is minimal $[10,11]$ and Drosophila's APP ortholog -APPL — has no A-beta sequence [12,13]. Thus expression of human APP in Drosophila allows estimating the effect of protein itself on Drosophila's development while its coexpressing with BACE results in A-beta production and deposition as shown in our previous study [8].

To investigate the effect of APP we expressed human APP695 gene and its mutant form APP-Swedish that leads to familial form of disease in brain cells of Drosophila melanogaster.

Expression of APP and APP-Swedish separately or together with BACE in Drosophila nerve cells resulted in abnormal development of fly imago, which manifested in black melanized spots on proboscis and abdomen, proboscis and mouthparts deformation, crumpled wings and abdomens swelled with hemolymph (Figure 1).

These flies died within 1 - 3 days of eclosion. Deformed proboscis and mouthparts (Figure 2) could be a cause of increased mortality rate of flies with morpho-

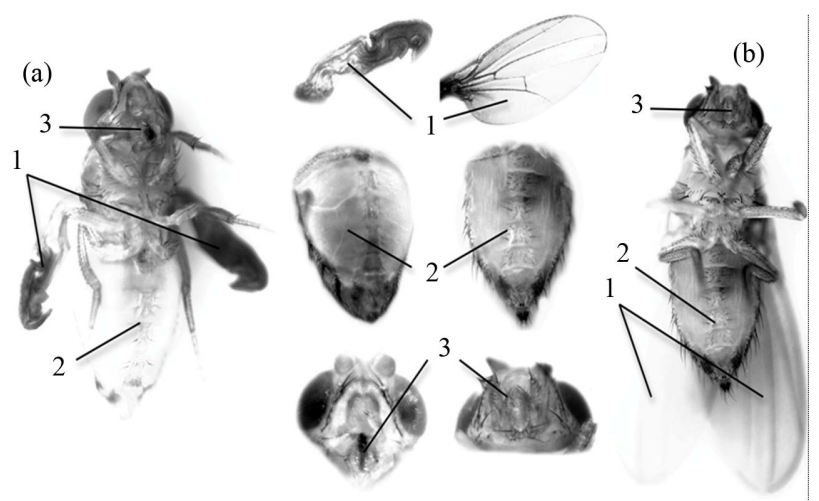

Figure 1. Morphological abnormalities in flies expressing human APP. (a) APP expression causes dramatical deformation and necrosis of proboscis and mouthparts, crumpled wings and swelled abdomen; (b) Control flies (elav; +; + ) have no morphological abnormalities. 1-wings, 2-abdomen, 3-proboscis and mouthparts.

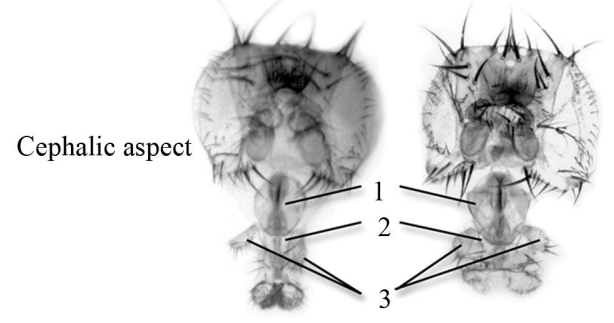

(a)

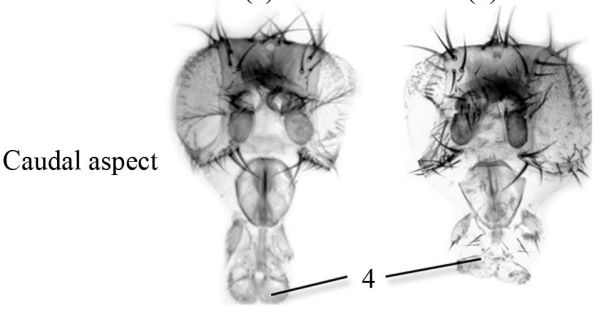

Figure 2. Proboscis and mouthparts deformation in flies expressing APP. (a) Control flies elav; +; + have no morphological abnormalities; (b) APP expression causes dramatical deformation of proboscis and mouthparts. 1-proboscis; 2-labrum; 3-maxillary pulps; 4-labellum and pseudotracheae.

logical abnormalities, because of inability to consume food.

We analyzed morphological abnormality frequency in flies within different genotypes cultivated on standard yeast medium as well as on yeast medium containing molasses with a higher calorie content to investigate whether calorie content can impact the frequency of morphological abnormalities (Figure 3).

Morphological abnormalities frequency strongly depended on a genotype. We observed more morphological abnormalities in flies expressing only APP. There was a significant drop in number of morphological abnormalities both in flies expressing APP-Sw and APP together with $B A C E$. Flies expressing both APP-Sw and BACE had significantly minimal number of morphological abnormalities. Medium containing molasses did not have any effect on the number of morphological abnormalities.

We suggest that the significant drop of morphological abnormality number in flies expressing both APP and $B A C E$ is due to the reduced level of APP in Drosophila nerve cells after the APP cleavage with BACE. We suggest that the smaller number of morphological abnormalities in flies expressing APP-Swedish is due to faster processing of the precursor.

We also measured pupal survival rate in transgenic flies (Figure 4) APP expression resulted in higher mortality of pupae, which indicates defects at the very early stage of Drosophila development. At the same time flies expressing APP-Swedish or APP and APP-Swedish to- 


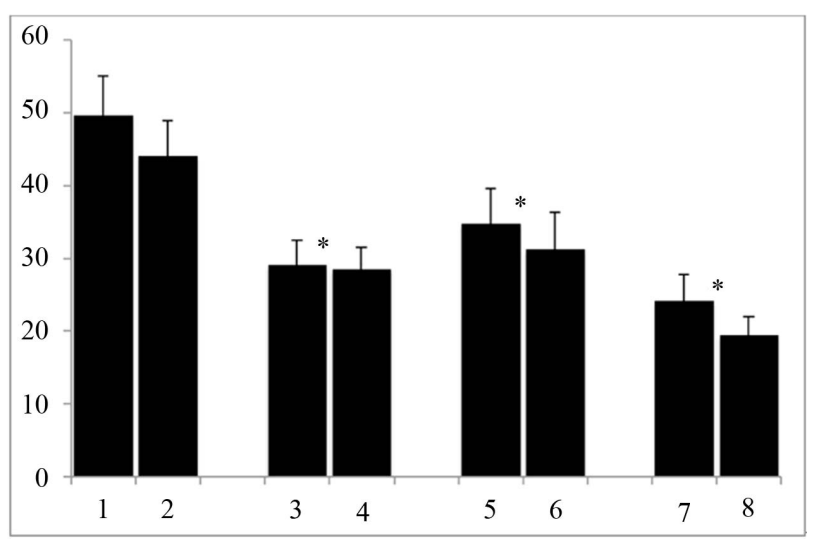

Figure 3. Morphological abnormalities frequency (\%) 1-elav; APP; 2-elav; APP + molasses, 3-elav; APP-SW, 4-elav; APP$\mathrm{SW}+$ molasses, 5-elav; BACE/APP, 6-elav; BACE/APP + molasses, 7-elav; BACE; APPSW, 8-elav; BACE; APP-SW + molasses. 1000 flies of every genotype were inspected. Asterisks indicate significant differences from elav; APP flies.

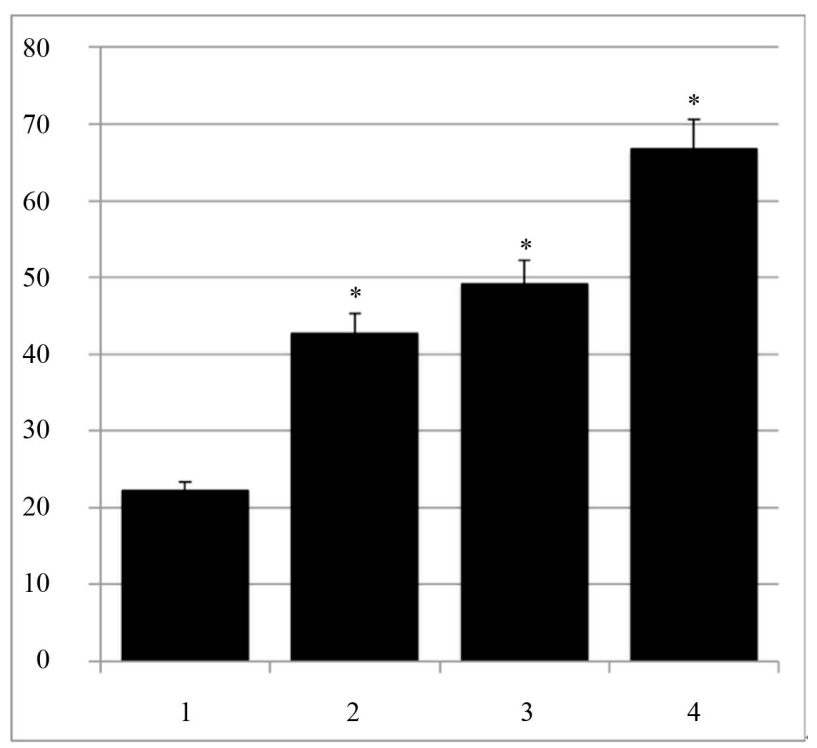

Figure 4. Pupal survival rate according to genotype (\%) 1-elav; APP, 2-elav; APP-SW, 3-elav; BACE/APP, 4-elav; BACE; APPSW. 1000 pupae of every genotype were inspected. Asterisks indicate significant differences from elav; APP flies.

gether with BACE had significantly better survival rate comparing to flies expressing only APP.

\section{DISCUSSION AND CONCLUSIONS}

Our data show that APP expression itself in nerve cells leads to severe pathological changes in Drosophila development that manifest not only in fly brain but also phenotypically as different morphological abnormalities.

Chakraborty et al. used the same transgenic fly lines to study developmental defects caused by APP expression [14]. Surprisingly he concluded that phonotypical changes described above are directly associated with production and deposition of A-beta in fly brains. Chakraborty et al. suggested that these abnormalities are caused by inflammatory response to A-beta deposits, which is controversial to our current data. In our study we showed that morphological abnormality frequency drops significantly in flies expressing A-beta comparing to flies expressing only full length APP or APP-Swedish. The high level of mortality in flies expressing APP or APP-Swedish (data not shown) and pupal survival rates confirm that it's not the A-beta factor but the expression of these genes leads to severe defects in fly development.

Such developmental defects can indeed be due to active immune response in transgenic flies. However, we suggest that this immune response is not activated by A-beta deposits but by full-length APP.

Green et al. observed similar morphological abnormalities - black melanized spots, abdomen swelled with hemolymph and high mortality rate (but not crumpled wings) - in flies with constantly activated Toll-mediated immune response [15].

Toll-like receptors (TLR) are a part of innate immune system. Their main function is to recognize conserved molecules of different microorganisms. Activating of Toll-mediated immune response results in activation of well-known transcription factors of NF- $\mathrm{kB}$ family. In case of Drosophila it activates transcription factors Dif and Dorsal. Grilli et al. identified two identical sequences in the 5'-regulatory region of APP, which are specific binding sites for transcription factors of NF- $\mathrm{KB}$ family. They also showed that activity of these sites correlates with APP expression [16].

Thus APP expression in flies can result in activation of NF-kB family protein, which in turn can lead to APP upregulation creating a loop in which expression of both participants is co-dependent.

Stante et al. showed that full length APP is necessary for activation of the FE65 protein and its translocation to the nucleus [17]. FE65 is essential for the recruitment of acetyltransferase TIP60 that plays a crucial role in DNA strand repair. They also showed that Fe65 suppression leads to a significant degree of chromatin de-condensation, which indicates that FE65 is involved in chromatin compaction. As activation of FE65 is dependent on interaction with APP, high levels of APP can lead to chromatin destabilization. However, it doesn't explain crumpled wings phenotype. We suggest that this phenotype can be due to competition between APP and its Drosophila ortholog APPL. Li et al. showed that APPL is necessary for the development of nonneural tissues such as wings and cuticles [18]. As APPL is expressed in the nervous system, crumpled wings phenotype can result from neuroendocrine dysfunction due to competition between APP and APPL.

Thus APP upregulation can negatively affect genomic 
stability and DNA repair processes as well as tissue development. There are many evidences showing that APP is overexpressed in different cancer types [19,20]. Genomic destabilization and tissue development defects resulted from APP overexpression can lead to morphological abnormalities in observed in transgenic flies.

\section{ACKNOWLEDGEMENTS}

The project is supported by the Russian Foundation for Basic Research (grant No. 12-04-00898). The authors sincerely thank R. Reifegerste for providing BACE Drosophila line.

\section{REFERENCES}

[1] Hardy, J. and Selkoe, D.J. (2002) The amyloid hypothesis of Alzheimer's disease: Progress and problems on the road to therapeutics. An updated summary of the amyloid hy-pothesis. Science, 297, 353-356.

http://dx.doi.org/10.1126/science.1072994

[2] Terry, R.D., Masliah, E. and Salmon, D.P. (1991) Physical basis of cognitive alterations in alzheimer's disease: Synapse loss is the major correlate of cognitive impairment. Annals of Neurology, 30, 572-580.

http://dx.doi.org/10.1002/ana.410300410

[3] Lee, H.G., Casadesus, G., Zhu, X., Joseph, J.A., Perry, G. and Smith, M.A. (2004) Perspectives on the amyloid-beta cascade hypothesis. Alzheimers Disease, 6,137-145.

[4] Nizzari, M., Thellung, S., Corsaro, A., Villa, V., Pagano, A., Porcile, C., Russo, C. and Florio, T. (2012) Neurodegeneration in Alzheimer disease: Role of amyloid precursor protein and presenilin 1 intracellular signaling. Journal of Toxicology, 2012, $13 \mathrm{p}$. http://dx.doi.org/10.1155/2012/187297

[5] Breen, K.C., Bruce, M. and Anderton, B.H. (1991) Beta amyloid precursor protein mediates neuronal cell-cell and cell-surface adhesion. Journal of Neuroscience Research, 28, 90-100. http://dx.doi.org/10.1002/jnr.490280109

[6] Gao, Y. and Pimplikar, S.W. (2001) The $\gamma$-secretasecleaved C-terminal fragment of amyloid precursor protein medi-ates signaling to the nucleus. Proceedings of the National Academy of Sciences of the United States of America, 98, 14979-14984. http://dx.doi.org/10.1073/pnas.261463298

[7] Szumiel1, I. and Foray, N. (2011) Chromatin acetylation, $\beta$-amyloid precursor protein and its binding partner FE65 in DNA double strand break repair. Acta Biochimica Polonica, 58, 8-11.

[8] Sarantseva, S., Timoshenko, S., Bolshakova, O., Karaseva, E., Rodin, D., Schwarzman, A.L. and Vitek, M.P. (2009) Apolipoprotein E-mimetics inhibit neurodegeneration and restore cognitive functions in a transgenic Drosophila model of Alzheimer's disease. PLOS One, 7, e8191. http://dx.doi.org/10.1371/journal.pone.0008191

[9] Bolshakova, O.I., Zhuk, A.A., Rodin, D.I., Kislik, G.A. and Sarantseva, S. V. (2013) The effects of overexpression of human APP on cholinergic and dopaminergic neurons of brain of Drosophila melanogaster. Ekologi- cheskaia Genetika Russia, 11, 23-31.

[10] Torroja, L., Packard, M., Gorczyca, M., White, K. and Bud-Nik, V. (1999) The Drosophila b-amyloid precursor protein homolog promotes synapse differentiation at the neuromuscular junction. The Journal of Neuroscience, 15, 7793-7803.

[11] Luo, L., Martin-Morri, L.E. and White, K. (1990) Identification, secretion, and neural expression of APPL-Drosophila protein similar to human amyloid protein precursor. The Journal of Neuroscience, 10, 3849-3861.

[12] Fossgreen, A., Bruckner, B., Czech, C., Masters, C.L., Beyreuther, K., et al. (1998) Transgenic Drosophila expressing human amyloid precursor protein show gammasecretase activity and a blistered-wing phenotype. Proceedings of the National Academy of Sciences of the United States of America, 95, 13703-13708. http://dx.doi.org/10.1073/pnas.95.23.13703

[13] Greeve, I., Kretzschmar, D., Tschape, J.-A., Beyn, A., Brellinger, C., et al. (2004) Age-dependent neurodegen-eration and Alzheimer-amyloid plaque formation in transgenic Drosophila. The Journal of Neuroscience, 24, 3899-3906.

http://dx.doi.org/10.1523/JNEUROSCI.0283-04.2004

[14] Chakraborty. R., Vepuri, V., Mhatre, S.D., Paddock, B. E., Miller, S., Michelson, S.J., et al. (2011) Characterization of a Drosophila Alzheimer's disease model: Pharma-cological rescue of cognitive defects. PLOS One, 6, e8191. http://dx.doi.org/10.1371/journal.pone.0020799

[15] Green, C., Levashina, E., McKimmie, C., Dafforn, T. Reichhart J.-M. and Gubb, D. (2000) The necrotic gene in Drosophila corresponds to one of a cluster of three serpin transcripts mapping at 43A1.2. Genetics, 156, 1117-27.

[16] Grilli, M., Ribola, M., Alberici, A., Valerio, A. and Memo, M., (1995) Identification and characterization of a kappa $\mathrm{B} /$ Rel binding site in the regulatory region of the amyloid precursor protein gene. The Journal of Biological Chemistry, 270, 26774-26777. http://dx.doi.org/10.1074/jbc.270.45.26774

[17] Stante, M., Minopoli, G., Passaro, F., Raia, M., Vecchio, L.D. and Russo, T. (2009) Fe65 is required for Tip60-directed histone $\mathrm{H} 4$ acetylation at DNA strand breaks. Proceedings of the National Academy of Sciences of the United States of America, 106, 5093-5098. http://dx.doi.org/10.1073/pnas.0810869106

[18] Li, Y., Liu, T., Peng, Y., Yuan, C. and Guo, A.J. (2004) Specific functions of Drosophila amyloid precursor-like protein in the development of nervous system and nonneural tissues. Neurobiology, 61, 343-358. http://dx.doi.org/10.1002/neu.20048

[19] Ko, S.Y., Lin, S.C., Chang, K.W., Wong, Y.K., Liu, C.J., Chi, C.W. and Liu, T.Y. (2004) Increased expression of amyloid precursor protein in oral squamous cell carcinoma. International Journal of Cancer, 111, 727-732. http://dx.doi.org/10.1002/ijc.20328

[20] Yang, Z., Fan, Y., Deng, Z., Wu, B. and Zheng, Q. (2012) Amyloid precursor protein as a potential marker of malignancy and prognosis in papillary thyroid carcinoma. Oncology Letters, 3, 1227-1230. 